\title{
O CINE: UN SECTOR CONVULSO
}

\section{Miguel Anxo Fernández}

Universidade de Vigo

Doi:10.17075/aceg.2016.005 

No informe anterior ${ }^{1}$ xa faciamos referencia á unha cuestión metodolóxica capital para unha análise do sector audiovisual en Galicia: a escaseza de fontes co rigor necesario para trazar unha radiografía de mínimos arredor da materia, a pesar da súa condición de industria cultural, polo tanto sometida a cifras e parámetros que deberían ser de dominio público. As circunstancias non mudaron desde aquela. Entre as consecuencias da crise económica, en particular no período aquí analizado, está a dun sector deprimido no que as produtoras que lograron manter a persiana aberta, evitando desaparecer do rexistro de empresas, optaron por centrar a súa estratexia de supervivencia na procura á desesperada dos recursos públicos (como é natural esta afirmación admite excepcións), a través das convocatorias anuais de estímulo á produción audiovisual (cadro 1) promovidas pola Axencia Galega das Industrias Culturais $(A G A D I C)^{2}$ ou na poxa polos recursos económicos que Televisión de Galicia destina para a produción allea. No sector audiovisual, que ten como os piares básicos da xeración de negocio o da produción (coas súas complexidades) e mais o da difusión e explotación (coas súas variantes de distribución, exhibición en salas, home cinema e Rede), escasean os datos que permitan unha ollada, cando menos, razoable por aproximada.

No tocante á produción, polo seu vínculo directo co contorno empresarial e profesional, existen os volumes bimensuais Papeis da Academia Galega do Audiovisual³, que desde o curso 2006/2007 promove a institución que lles dá nome, e as memorias anuais da Asociación Galega de Produtoras Independentes (AGAPI) ${ }^{4}$, quedando só o recurso das fontes xornalísticas a través dos seus diferentes soportes, xa que o institucional Observatorio Audiovisual Galego ${ }^{5}$ mantense inactivo desde 2010, igual que a web do outro colectivo profesional, a Asociación de Empresas Galegas do Audiovisual (AEGA) ${ }^{6}$. Cómpre engadir, a maiores, a achega da citada AGADIC, o organismo que desde 2012 asume as competencias de política audiovisual da Xunta de Galicia e que recolle no seu portal ${ }^{7}$ non só as novas derivadas da xestión propia, senón tamén outras vinculadas ao sector privado, incluíndo o acceso virtual á oferta do Centro Galego de Artes da Imaxe (CGAI)-Filmoteca de Galicia, por estar agora incorporado administrativamente ao seu organigrama.

1 Xosé López García / Manuel Rivas Barrós / Rosa Aneiros Díaz (coords.) (2013): A comunicación en Galicia 2013, Santiago de Compostela, Consello da Cultura Galega, 119-131.

20 miúdo das correspondentes á produción de longametraxes en 2013 poden consultarse en http://www.agadic.info/gfx/axudas/ axudas_prod_av resolucion_13.pdf e as do ano seguinte en http://www.agadic.info/gfx/axudas/axudas_producion_audiovisual_resolucion $\overline{14}$.pdf.

3 Dispoñible toda a serie en https:/www.academiagalegadoaudiovisual.com/publicacions/page/2l. Constitúen en si mesmo unha panorámica interesante do sector, dado que recollen opinións, estatísticas, novas, premios, balances. Con todo, o seu carácter achégase máis á reflexión que a unha vocación clara de balance anual global. Cómpre ter en conta que a Academia é un club privado de adscricións voluntarias e non engloba a todos os profesionais do sector.

4 http://www.agapi.org/v2/portada.php. A súa web amósase moi activa, recollendo novas do audiovisual galego en xeral, con especial atención ás xeradas polos seus asociados, ademais de convocatorias, premios... Agrupa 18 empresas, que non son a totalidade do sector, aínda que entre elas está a de maior rendibilidade por venda de billetes nos últimos anos pola súa participación en filmes como El niño, que en 2014 deixou uns ingresos brutos en salas de 16175 804,74, desde a súa estrea o 28 de agosto de 2014 (Consultado o 3 de febreiro de 2015 en https://www.mecd.gob.es/bbddpeliculas/buscarDetallePeliculas.do?brscgi_DOCN=000046857\&brscgi_BCSID $=92$ dbeaea\&language $=$ es\&prev_layout=bbddpeliculasResultados\&layout=bbddpeliculasDetalle).

5 En www.observatorioaudiovisual.org, que non actualiza datos desde 2010, figura como «servizo da Secretaría Xeral de Medios da Presidencia da Xunta de Galicia».

6 http://www.aega.tv/ (Consultada o 17 de febreiro de 2015).

7 http://www.agadic.info/. 
Igualmente, o eido da difusión caracterízase por unha desigual opacidade, aínda que a existencia do control de billetes vendidos por parte do Ministerio de Educación, Cultura y Deporte permite, polo menos, que se poida ter información puntual e rigorosa do resultado económico da explotación dos filmes galegos en salas, así como do número destas en varios parámetros (por provincia, por comunidade...) a través do seu sitio web ${ }^{8}$. 0 escurantismo instálase de cheo na explotación dos filmes para o home cinema e mais no servizo de descarga legal de filmes online en streaming (non se difunden publicamente datos do número de copias vendidas e de descargas), modalidades ás que xa se incorporou o produto galego con asiduidade. Por iso, radiografar o sector audiovisual segue a ser tarefa titánica con moito de especulativa.

\section{MÁIS CINE PROPIO NAS PANTALLAS PROPIAS}

Así e todo, é ben certo que se poden facilitar algúns datos obxectivos do bienio 2013-2014, que, cando menos, permiten asegurar que a normalización do sector xa non é tarefa pendente, que o talento agroma, que hai resultados parciais que invitan ao optimismo, sobre todo na acollida popular e tamén crítica a algúns filmes, previo o seu paso polas pantallas. Con todo, e á vista do cadro 2, hai que facer un alto para precisar que este período se abriu mantendo os atrancos de acceso ao circuíto exhibidor comercial, dado que o cine galego non se afasta das dificultades do español e do pertencente a terceiros países, á marxe da predominante industria estadounidense. Por esa razón, o extraordinario éxito económico de El Niño, que foi o segundo filme español máis visto do ano ${ }^{9}$, participado por Vaca Films Studio, empequenece en moito a salientable acollida de El club de los incomprendidos, coproducida por Bambú Films, e ao tempo reduce á mínima expresión o resultado de $A$ esmorga, promovida desde Vía Láctea Films, pero que, ao estrearse só en versión galega en Galicia (certamente de modo masivo), fai que os case 50000 espectadores acadados desde a súa estrea sexan unha moi considerable cifra. Da mesma maneira, cómpre matizar que o limitado resultado de boa parte dos filmes se debe a unha estrea moi restrinxida, mesmo nalgún caso en sesións limitadas.

Precisamente, no eido da exhibición aconteceron feitos de interese, en parte encamiñados a crear ventás abertas ao cine alleo contra do abafante made in Hollywood, tanto desde a banda institucional como da iniciativa privada en canto a difusión do produto propio en salas. Desde finais de 2014, a AGADIC promove o programa Cinemas de Galicia, «unha rede de salas públicas para a exhibición cinematográfica impulsada [...] coa finalidade de incrementar tanto o número de pantallas da Comunidade, como as opcións de distribución dos filmes galegos máis recentes», engadindo a súa pretensión «de facilitarlle ao público galego a oportunidade de gozar en pantalla grande dunha escolma de filmes que, malia a súa contrastada calidade, non son doados de atopar nos circuítos comerciais» ${ }^{10}$. Dese modo, xa a comezos de 2015, vilas carentes de salas comerciais, como son 0 Carballiño, Verín, Sanxenxo, Redondela, Ortigueira, As Pontes e Foz, contribúen á visibilidade do outro cine, o galego incluído, ás que se sumarán outras vilas no futuro. A maiores, en marzo de 2015, despois dun prolongado tempo de maduración neste bienio, abriuse en Compostela o espazo Numax, que oferta unha sala especializada en cine de autor en versión orixinal con lendas, oferta tamén asumida polas cinco pantallas dos Multicines Norte, en Vigo. Convén engadir, a maiores, a total reconversión dixital do parque exhibidor galego, incluídas as salas chamadas periféricas polo seu asentamento en vilas. Desa maneira, Galicia dispuña de 170 pantallas en 2014, pouco máis do $4 \%$ das 3908 existentes en España, cunha perda de 14 con relación ás existentes un ano antes (cadro 3). En canto á asistencia

8 http://www.mecd.gob.es/cultura-mecd/areas cultura/cine/inicio.html;jsessionid=87EFEE0418B48F00D5E4C0D8E1F91E67.

9 Ocho apellidos vascos foi a máis vista de 2014, acadou o récord de toda a historia do cine español con 9346289 espectadores e unha recadación bruta de $55163074,90 €$.

10 http://www.agadic.info/cinemasdegalicia. 
ás salas por parte dos espectadores galegos, a proporción sitúase por debaixo do 4 \% durante o bienio (cadro 4), apenas mellorado en 2014, en boa parte polo récord histórico de recadación acadado polo filme Ocho apellidos vascos, de Emilio Martínez Lázaro ${ }^{11}$.

\section{UNHA DIFUSIÓN PLURALIZADA}

Da mesma maneira, no aspecto da difusión, á parte das pantallas, hai outras canles que tamén axudan á visibilidade do cine galego, sobre todo as mostras e festivais de periodicidade anual, que, con desigual incidencia pero sen abeirar o produto propio, poñen o foco no audiovisual do país integrándoo nas súas programacións, contribuíndo igualmente á promoción dos seus autores. Velaí Cans (O Porriño), Play-Doc (Tui), Cineuropa (Santiago de Compostela), Curtocircuito (Santiago de Compostela), s8 Mostra de Cine Periférico (A Coruña), Ourense Film Festival (Ourense), Festival Amal (Santiago de Compostela) e, en menor medida pola súa crise neste período, as históricas Xociviga do Carballiño. De xeito máis voluntarioso, pero igualmente efectivo para a difusión das creacións audiovisuais propias, engadiríanse as mostras de curtas que se propoñen en Bueu, Noia, Carballo e outras vilas galegas, así como as semanas de cine e programacións regulares que ofertan os doce colectivos repartidos polas provincias galegas, nalgún caso en poboacións carecentes de sala comercial, e integrados na Federación de Cine Clubs de Galicia ${ }^{12}$ (cadro 5). Finalmente, desde o ámbito universitario, sumándose tamén á difusión de filmes e autores propios, concretamente desde a Universidade de Vigo, cómpre salientar o asentamento do Curso de Medios Audiovisuais de Celanova (CEMAC), promovido coa Fundación Carlos Casares, e mais Augal. Audiovisual Galego, en Pontevedra co apoio da AGADIC.

Habería que mencionar, tamén, os voceiros especializados. Desaparecida en 2011, AG, Revista do Audiovisual Galego en soporte papel, saliéntase a consolidación de Scifiworld, ben asentada no mercado español, desde a súa fundación en 2005, editada en castelán desde Galicia, e centrada en xénero fantástico. 0 afianzamento da Rede e a mellora de custos que iso posibilita, fronte ao modelo tradicional de medios impresos, provocaron interesantes espazos de información e debate, como son a revista dixital A Cuarta Parede, o blog Acto de Primavera e o soportal do audiovisual galego AVG, ao abrigo do Consello da Cultura Galega, como as máis salientables e asentadas no bienio analizado ${ }^{13}$.

\section{UNHA FERVENZA DE CREADORES}

No referido ao talento, nos últimos anos semella confirmarse un interesante relevo, xeracional pero tamén creativo, que permite manterse expectantes ante o porvir do audiovisual propio. Tomando como base o formato longametraxe e como data referencial a de 1989, coa estrea das tres primeiras obras galegas e en galego: Sempre Xonxa (Chano Piñeiro), Urxa (Carlos A. L. Piñeiro, Alfredo Ga Pinal) e Continental (Xavier Villaverde), desde aquela considero que os cineastas galegos poden repartirse en catro grupos que, na miña opinión, serían os pioneiros, os de transición, os eclécticos ${ }^{14}$ e o cuarto grupo que xa reuniría os máis novos, "cunha bifurcación que incluiría aos que se dan en

${ }^{11}$ Con 9378221 espectadores, que deixaron a cantidade bruta de 55287 050,75 millóns de euros de recadación.

12 http://www.feciga.org/.

${ }^{13}$ Cfr. Jaime Pena (2014): «Signos de vida. 1989-2014», no catálogo da exposición Cinegalicia25, Santiago de Compostela, Xunta de Galicia, 88-101.

${ }^{14}$ Para maior detalle sobre o citado agrupamento autoral, consúltese Miguel Anxo Fernández (2014): «Galicia e o cine. Diversidade e identidade na procura de acomodo», Grial, 204, outubro, novembro, decembro, 13-27. 
etiquetar como Novo Cinema Galego (NCG), con propostas claramente abeiradas ata a expresión experimental»15. Entre os primeiros, con filme neste bienio, estarían Alfonso Zarauza, autor de Encallados (2013) e Os fenómenos (2014); Álex Sampayo (Schimbare, 2014); Alejandro Marzoa (Somos gente honrada, 2013); Isabel Ayguavives (El árbol magnético, 2013) e Carlos Sedes (El club de los incomprendidos, 2014), xunto a outros que durante este tempo non asomaron con obra longa ${ }^{16}$.

Parellos a eles, pero encadrados desde 2009 na marca Novo Cinema Galego, que non outorga patentes de adhesión nin acorda pautas programáticas, máis alá dunha certa mestizaxe de estilos, orixes e pretensións na modalidade de produción low cost, estrearían neste período autores como Lois Patiño (Costa da Morte, 2013), Ángel Santos (Las altas presiones, 2014) e Alberto García (O Quinto Evanxeo de Gaspar Hauser, 2013), xunto a Marcos Nine co documental de montaxe $A$ viaxe de Leslie (2014). O citado grupo achega outros nomes de variada praxe e ton, como Oliver Laxe, Eloy Enciso, Xurxo Chirro, Peque Varela, Marcos Nine, Eloy Domínguez Serén, Víctor Hugo Seoane, Olalla Castro e Fran Estévez, entre outros, que, aínda sen pertencer «de facto» ao NCG, si apostan por introducir un selo persoal de autor, moitos apoiados por produtoras cómplices, con Zeitun Films á cabeza xunto a outras na mesma liña ${ }^{17}$. Paradoxalmente, apréciase un interese pouco entusiasta en dotar esas imaxes da lingua propia, cuestión irrenunciable para dotar do seu carácter primixenio o cine galego, pero ese xa é outro debate que aquí non corresponde afrontar a pesar de ser preocupante polo que supón de rexeitamento á necesaria clave identitaria.

Como é natural, xunto a esta xenerosa nómina de creadores novos, permanece o restante espectro autoral, algúns xa con dilatada traxectoria e con filmes estreados entre 2013 e 2014, como son Xavier Bermúdez, con 0 ouro do tempo (2014); Juan Pinzás, con Sombras de Nueva York (2013); Jorge Algora, con Inevitable (2013); Margarita Ledo, con A cicatriz branca (2013), e Ignacio Vilar, con A esmorga (2014). E a participación en El niño (Daniel Monzón, 2014) de Vaca Films Studio, produtora que, xunto a Zircozine, son quizais as máis activas neste período cronolóxico no relativo a promover obra no formato grande. Da mesma maneira, habería que anotar o relativo baixón no protagonismo que Galicia viña mantendo na animación (o último Goya duplo foi en 2011 para Arrugas, coprodución da xa desaparecida Perro Verde), con dúas últimas achegas, La tropa de trapo en la selva del arco iris (2014), coproducida por Abano Films, e a chegada a porto, non sen tempo, da accidentada Holly Night ${ }^{18}$, do cambadés Juan Galiñanes, que a desaparecida produtora Dygra tiña previsto estrear en 2012 na modalidade 3D e que, finalmente, puido facer o propio Galiñanes en condicións titánicas.

En todo caso, a finais de 2014, cumpríase un cuarto de século de cine galego desde que en novembro de 1989, na mostra Cinegalicia desenvolvida en Vigo, se estrearan as tres primeiras longas galegas. Con tal motivo, artellouse na Cidade da Cultura, en Santiago de Compostela, a exposición Cinegalicia25, co ánimo de pór en valor o inxente valor do feito nese tempo por parte do sector audiovisual, acompañada dunha publicación que xurdía coa vocación de obra de referencia ${ }^{19}$ de cara a reafirmarse nun proceso que xa é irreversible: a dun audiovisual propio coa intención de ter presenza no mundo global como sinónimo dun país e da súa sociedade.

\footnotetext{
${ }^{15}$ Fernández, op. cit., 2014, 24.

${ }^{16}$ Casos de Jorge Coira, Luis Avilés, Sandra Sánchez e, mesmo, o ourensán Rodrigo Cortés, debutante coa rodaxe en Galicia de Concursante (2007) e lanzado ao mercado internacional co seu filme seguinte, Buried (2010).

17 Frida Films, Tic Tac, Portocabo...

18 Dygra Films pechou en xaneiro de 2012 e o negativo do filme foi embargado, acabou en propiedade de Abanca. Galiñanes conseguiu que a entidade bancaria accedese a cederlla para estreala de xeito restrinxido e «case heroico» o 7 de novembro de 2014.

19 VV. AA. (2014): Cinegalicia 25, Santiago de Compostela, Xunta de Galicia, 262. Con ensaios de Miguel Anxo Fernández, Xosé
} 


\section{UN FUTURO NA PROCURA DE ACOMODO}

Un dos efectos da crise económica arrastrada desde 2008 foi o de manifestarse na súa dureza, sobre todo entre 2012 e 2013, co peche irreversible de moitas produtoras, algunhas quizais asentadas sobre unha estrutura feble e en exceso acomodada ao subsidio público. Igualmente, houbo outras que tiveron que someterse a unha dolorosa reconversión. Como en calquera catarse, a convulsión deu paso a numerosas mudanzas en todas as ordes, pero o audiovisual propio mantense vivo, cunha achega a maiores de afloramento de talento, mentres na praxe empresarial tamén se produciron interesantes axustes de cara a afrontar un futuro distinto nunha comunidade cada vez máis globalizada. 0 noso audiovisual asume a racionalización de recursos e mais rigor nos proxectos que afrontar; tamén a necesidade de procurar coprodución externa e a aspiración de ser competitivos. A crise non desanimou os produtores e boa proba diso son os numerosos proxectos que anualmente saen beneficiados das axudas institucionais da Xunta de Galicia a través da AGADIC e mais da demanda de contidos de TVG, sen dúbida o principal motor do audiovisual galego, a pesar de rebaixar investimentos en produción allea. Para máis, a formación de profesionais novos está ben garantida desde o ámbito universitario e a formación especializada, malia as dificultades de reinserción laboral, certamente en niveis aínda alarmantes. Cómpre, iso si, idear e redefinir unha maneira de ver o mundo desde Galicia a través das imaxes, que permita asomar produtos singulares capaces de competir no mercado global, sen esquecer que o sector audiovisual galego está considerado estratéxico desde a promulgación da Lei do audiovisual en 1999. Como tamén asumir que a singularidade e a diferenza pasan por non renunciar á lingua propia. Son debates aínda pendentes.

Unha das consecuencias do bo ano que supuxo 2014 para o cine español foi romper co tópico de que o público propio non comungaba co seu cine. As cifras de asistencia e as cantidades recadadas confirman que tal cousa semella superada, sen deixar de recoñecer que niso tamén axudou a achega promocional de grandes grupos televisivos como Mediaset España Comunicación ${ }^{20}$ e Atresmedia Corporación, coprodutores de varios dos filmes. A unha escala máis modesta, recolleuse tamén en Galicia, onde $A$ esmorga foi capaz de levar miles de persoas ás salas cun produto presentado en galego con capital galego. Se hai pantallas, haberá público. Nese senso, as 170 pantallas computadas en 2014, coas que a exhibición galega tocaba fondo, xa están a ser amplamente superadas no ano 2015, tanto polas achegas da iniciativa privada como pola institucional; da mesma maneira que as previsións de estreas cinematográficas desde Galicia para o tempo inmediato permiten agardar presenza nesas pantallas con garantías de boa acollida. Ben é certo que aínda falta por superar o asunto da promoción e mais o da introdución do audiovisual nas aulas, sobre todo como nutriente cultural e como contribución á conciencia dun cine de seu nas futuras xeracións, necesario non só como canle de expresión, senón tamén para o mantemento da propia identidade como país. E niso convén andar.

Cadro 1. Subvencións de AGADIC para producións e coproducións en varios formatos

\begin{tabular}{cc}
2013 & 2014 \\
\hline 0 producións & 13 producións \\
\hline
\end{tabular}

Fonte: AGADIC.

Nogueira, Eduardo Galán, Jaime Pena e Xosé Enrique Acuña. 
Cadro 2. Resultados na recadación das coproducións galegas 2013-2014

\begin{tabular}{|c|c|c|c|c|c|c|c|}
\hline $\mathrm{N}^{\circ}$ & Título & Director & Coprodutora galega ${ }^{21}$ & Estrea & Espectadores & Recadación/€ & Outros \\
\hline 1 & EL NIÑO & Daniel Monzón & Vaca Films Studio & 28.8 .2014 & 2749173 & 16175804,74 & \\
\hline \multirow[t]{2}{*}{2} & EL CLUB DE LOS & Carlos Sedes & Bambú Producciones & 12.12 .2014 & 329142 & 2142351,31 & \\
\hline & INCOMPRENDIDOS & & & & & & \\
\hline \multirow[t]{2}{*}{3} & A ESMORGA & Ignacio Vilar & Vía Láctez Films, & 21.9 .2014 & 46842 & 272583,66 & \\
\hline & & & Editorial Galaxia & & & & \\
\hline \multirow[t]{2}{*}{4} & SOMOS GENTE & Alejandro Marzoa & Vaca Films Studio & 14.6 .2013 & 24841 & 150613,66 & \\
\hline & HONRADA & & & & & & \\
\hline \multirow[t]{2}{*}{5} & OS FENÓMENOS & Alfonso Zarauza & Zircozine, Tic Tac, & 11.12 .2014 & 15271 & 90351,13 & \\
\hline & & & Maruxina Film Company & & & & \\
\hline \multirow[t]{2}{*}{6} & EL ÁRBOL & Isabel Ayguavives & 235 Producciones & 25.11 .2013 & 1385 & 7016,95 & \\
\hline & MAGNÉTICO & & & & & & \\
\hline \multirow[t]{3}{*}{7} & LA TROPA DE & Álex Cols & Abano Producciones, & 30.4 .2014 & 5476 & 21919,19 & \\
\hline & TRAPO EN LA SELVA & & Continental Producciones & & & & \\
\hline & DEL ARCO IRIS & & & & & & \\
\hline 8 & COSTA DA MORTE & Lois Patiño & Zeitun Films & 26.9 .2014 & 3205 & 14769,40 & \\
\hline \multirow[t]{3}{*}{9} & INEVITABLE & Jorge Algora & Adivina Producciones & 10.4 .2014 & 2877 & 15688,04 & Tamén \\
\hline & & & & & & & estreada na \\
\hline & & & & & & & Arxentina \\
\hline \multirow[t]{3}{*}{10} & LAS ALTAS & Ángel Santos & Matriuska Producciones & 7.5.2015 & 1862 & 9120,80 & Presentada \\
\hline & PRESIONES & & & & & & en festivais \\
\hline & & & & & & & en 2014 \\
\hline 11 & LOS INCREÍBLES & David Valero & Frida Films & 28.11 .2013 & 811 & 2440,60 & \\
\hline 12 & O OURO DO TEMPO & Xavier Bermúdez & Xamalú Films & 1.8.2014 & 769 & 3711,90 & \\
\hline \multirow[t]{2}{*}{13} & A CICATRIZ BRANCA & Margarita Ledo & Nós Produtora & 30.8 .2013 & 378 & 2282,40 & \\
\hline & & & Cinematográfica Galega & & & & \\
\hline \multirow[t]{2}{*}{14} & SOMBRAS DE & Juan Pinzás & Atlántico Films & 14.6 .2013 & 135 & 949,60 & \\
\hline & NUEVA YORK & & & & & & \\
\hline 15 & O QUINTO EVANXEO & Alberto García & Zeitun Films & 30.13 .2014 & 46 & 140 & \\
\hline & DE GASPAR HAUSER & & & & & & \\
\hline
\end{tabular}

Fonte: Instituto de Cinematografía y de las Artes Audiovisuales, ICAA.

Cadro 3. Salas de exhibición en Galicia. 2013

\begin{tabular}{cccccc} 
& A Coruña & Lugo & Ourense & Pontevedra & Total \\
\hline $\mathbf{2 0 1 3}$ & 86 & 23 & 12 & 63 & 184 \\
\hline $\mathbf{2 0 1 4}$ & 80 & 16 & 12 & 62 & 170 \\
\hline
\end{tabular}

Fonte: Instituto de Cinematografía y de las Artes Audiovisuales, ICAA.

20 Participou como coprodutora en Ocho apellidos vascos e El Niño, os dous filmes españois máis vistos en 2014.

21 Boa parte delas inclúen a TVG como coprodutora ou participada, ademais de subvención da Xunta de Galicia a través da AGADIC. 
Cadro 4. Espectadores e recadacións nas salas de Galicia. 2013/2014

2013

\begin{tabular}{lrr}
\hline & Espectadores & Recadación \\
\hline A Coruña & 1588438 & 10177775,86 \\
\hline Lugo & 264295 & 168396,80 \\
\hline Ourense & 218131 & 1508531,95 \\
\hline Pontevedra & 949049 & 6476758,94 \\
\hline TOTAL & 3019913 & 19847027,55 \\
\hline \multicolumn{3}{c}{$\mathbf{2 0 1 4}$} \\
\hline A Coruña & 1850333 & 10732602,34 \\
\hline Lugo & 283934 & 1682516,70 \\
\hline Ourense & 269739 & 1642031,70 \\
\hline Pontevedra & 1208743 & 7217525,15 \\
\hline TOTAL & 3617749 & 21274675,89
\end{tabular}

Fonte: Instituto de Cinematografía y de las Artes Audiovisuales, ICAA.

Cadro 5. Cineclubs en Galicia. 2014

\begin{tabular}{cccc} 
A Coruña & Lugo & Ourense & Pontevedra \\
\hline 1 & 3 & 3 & 5 \\
\hline TOTAL: 12 & &
\end{tabular}

